International Journal of English Literature and Social Sciences
Vol-6, Issue-4; Jul-Aug, 2021

Peer-Reviewed Journal

\title{
The impact of stress on the mental health of people: Advancing our understanding of race-related stressors
}

\author{
Rajesh Rishi ${ }^{1}$, Pinki Doloi ${ }^{2}$
}

\begin{abstract}
${ }^{1}$ Deptartment of Electrical and Electronics Engineering, Assam Don Bosco University, Airport Road, Azara, Guwahati - 781 017, Assam, India.

${ }^{2}$ Department of Computer Science Engineering, North Eastern Regional Institute of Science and Technology (NERIST), Nirjuli - 791 109, Arunachal Pradesh, India.
\end{abstract}

Received: 21 Jun 2021; Received in revised form: 13 Jul 2021; Accepted: 19 Jul 2021; Available online: 29 Jul 2021 C2021 The Author(s). Published by Infogain Publication. This is an open access article under the CC BY license (https://creativecommons.org/licenses/by/4.0/).

\begin{abstract}
This study provides a summary of study on racial stress factors which may impact the wellbeing of communally stressed race-related individuals and also cultural populaces. That starts with evaluating the assessment on self-exposed parting and mental wellness. Even though the information which is segregation is the mainly observed part of mental wellness, discrimination can also affect mental wellness with most important elements and discrimination which is extremely bordered in the larger society. The main essentials for study include more purposeful consideration of stress development measures as a result of institutional racism, the evaluation of difficult understanding related to normal and synthetic all-natural emergencies, archiving and recognizing the wellness influences of aggressiveness opposite to immigrants, listing and also assessing defensive possessions, and also boosting our comprehension of the bewildering partnership amongst physiological wellness.
\end{abstract}

Keywords-Race, stress and anxiety, racial discrimination, racism, emotional health, and mental disorders.

\section{INTRODUCTION}

There are significant inside and outside in the business in amid race as well as moreover emotional wellness. In few years, study has, truthfully, disclosed that while continually have far better stages of emotional stress compare to whites, few researches, additionally, situate that whites have actually elevated stages of anxiety along with added stress as well as additionally tension in addition to stress and anxiety symptoms and signs along within similar way indications contrasted to blacks (Dohrenwend 1969, Vega in addition to in addition Rumbaut 1991).

Blacks often tend to report reduced degrees of health and on the cognitively focused jobs such as live full satisfaction together with complete satisfaction (Hughes along with Thomas 1998), yet in a comparable technique, paper greater stages of innovation compare to whites
(Keyes 2007), the deficiency of psychological concerns and the existence of obvious stages of psychological success

When it associates with specified psychological problems, Hispanics, with the exclusion of Puerto Ricans, blacks, in addition to furthermore orientals every one have actually reduced rates of a lifetime along with previous year psychological issues compare to whites (Miranda et al. 2008).All the same, while blacks and also Latinos understands the psychological concern, their scenes will as a whole be are much more significant, persist for longer durations, and also are more disabling than for another racial event (Breslau et al. 2005). 


\section{RACIAL DISCRIMINATION AND MENTAL HEALTH}

Individuals of color in addition to all those whose lives have in reality been marginalized by those in power experience life in lots of methods from those whose lives have in truth not been reduced the well worth of. They experience recognizable racism together with racism much regularly, which produces a psychological illness that is much deeper than what others could look after.

Previous injury is clearly specified as the variable that individuals experience considerable mental health problems today. [1] The noticeable kind of racism together with racism is just the concept of the iceberg when it includes racial injury.

In existing years, research study on racial discrimination together with psychological wellness as well as likewise health has in reality been a rapidly climbing location of medical analysis. Race-related discrimination is finest acknowledged as best courses where racial impacts the wellness and also health (Williams along with furthermore Mohammed 2013). The word "racism" specifies a wellorganized arrangement which is thought upon the classification together with moreover, furthermore, the positioning of social teams right into race (Bonilla-Silva 1996). The top categories minimizes, disallow, along furthermore disparity designates better social adjustments together with consisted of resources to racial groups acknowledged as substandard. There is a massive body of sophisticated expert proof that records the self-constraint of racial discrimination in the job, framework, economic, in addition to various other bargains, together with a massive variety of domain name of life (Pager as well as in addition on top of that Guard 2008).

\section{EARLY EMPIRICAL SYUDY UPON RACE- RELATED DISCRIMINATION}

Early assessment of segregation and wellness located that self-observation proportions of splitting up were otherwise correlated through excellent psychological health. Testimonies of these incredibly very early makeups subjected that many checks out were cross-sectional, several had a look at emotional health results or several various other self-reported signs of wellness in addition to health and wellness and also wellness in addition to wellness as well as health, along with most of the concentrate on African American miss in the US.

\section{RECENT EMPIRICAL STUDY UPON MENTAL HEALTH AND DISCRIMINATION - ADULTS}

A new survey explored to segregation is absolutely gotten in touch with percentages of anguish as well as anxiety signs and psychological discomfort, equally as, with identified psychological concerns (Lewis, Cogburn, in addition to furthermore Williams 2015). In the NSAL, amongst African American in addition to additionally, Caribbean Black miss 55 years in addition to older, useful nevertheless little company showed up in between both racial and non-racial daily discrimination in addition to moreover the threat of any type of kind of lifetime (LT) trouble, together with LT mindset, and anxiety troubles. Discrimination was furthermore gotten in touch with a little enhanced threat of troublesome symptoms as well as genuine psychological anguish (Mouzon et al. 2017).

\section{EMPIRICAL STUDY UPON MENTAL HEALTH AND DISCRIMINATION - ADULTS}

The study exposed to visibility to separation and there damaging outcomes for mental wellness starting throughout day-to-day life. This study reviewed that discrimination amongst young people and teens, subjected 121 kinds of the research study (and four hundred sixty one consequences) that have observed the involvement among separation and wellbeing amid individuals zero to eighteen yrs of ages (Priest et al. 2013). Visibility to splitting up prepared for more terrible psychological wellness (e.g., anxiety and grief adverse effects) in $76 \%$ of the one hundred twenty seven relations observed. Furthermore, prejudice was otherwise gotten in touch with favorable psychological wellbeing (e.g., versatility, selfconfidence) in $62 \%$ of the 108 associations examined. As an example, research in countryside Georgia of seven hundred fourteen dark teens, developed ten to twelve at scale, reviewed their visibility to splitting up numerous times throughout the complying with 5 yrs (Brody et al. 2006 ). It discovered that developments in race-related segregation were connected with straight issues and also troublesome symptoms, with the connection amongst splitting up and also lead problems a lot more based for boys nonetheless no sexual preference distinction noticeable for troublesome adverse effects (Brody et al. 2006 ).

Some investigation suggested that guardian frankness to discrimination may antagonistically influence the kid. For example, a research of dark teens located that guardian race-related partition be linked through signs of stress and grief in the childrens without the youngster's understandings of race-related discrimination (Gibbons et al. 2004). One more examination of ten and eleven years 
olds discovered that mom records of race-related prejudice were connected with bad guardian emotional wellness, hence antagonistically affected parenthood practices and also parenthood gratification (Murry et al. 2001).

although race-related discrimination is associated by unfavorable psychological health implications for both sexes, man and also women Black young people comparison regarding long run influences of an increment in saw discrimination on degeneration of psychological signs. Dark people seem a lot more prone than Black females to the psychological effects of an increment in race-related discrimination over the upcoming days (Assari et al. 2017).

\section{AWARENESS AND THE RISK OF EXPOSURE TO DISCRIMINATION}

Careful adapting strategies intervened in the relationship between discrimination and anxiety. Multi-bunch method assessment revealed that anxiety, therefore, was associated with increased frustration in individuals. Self-exposed wellness consequences of anxiety various between individuals.Vigilance-adapting steps in the relationship amongst discrimination and distress, and distress has subdivisions for wellness outcomes coming in regards to discrimination. More research is required to understand various other invisible upholders of discrimination, distress, and persistent fault outcomes most eventually interventions to boost health outcomes despite partition relevant stress (Himmelstein et al. 2015).

Discrimination, as various stress factors, may affect wellness with two real visibility and the threat of visibility. Raised carefulness mentions residing in a problem of psychological exhilaration to display, react toward, and undertaking to defend ourselves out of danger attached to most likely understandings of discrimination and various risks in one's neighboring surroundings (Williams, Lavizzo-Mourey, and also Warren 1994). The Elevated observation range was produced like a associate step to the daily separation Range as well as attempts to capture ventures to secure ourselves as of discrimination and limitation visibility (Williams et al. 1997). Research by the range and constricted variations of it highlight the meaning of looking over the prosperity aftereffects of racial alertness. The assessment discovers that racial caution is distinctly associated with immense vein adaptability (a preclinical record of cardiovascular limit) with regards to African American boy anyway not young woman (Clark, Benkert, and Flack 2006), the threat of rest complexity, and race-related irregularities in rest, the probability of stress for blacks and Hispanics yet not whites, and the race-related opening in anxiety (Hicken et al. 2014) and midriff circuit and body mass index amongst ethnic minorities (Hicken, Lee, and Hing 2018).

Watchfulness moreover issues for psychological wellness. An examination of Baltimore grown person observed that blacks have more huge degrees of inspired mindfulness compare to whites, and watchfulness was emphatically related through troublesome appearances and added to the dull white uniqueness in hopelessness (Laveist et al. 2014). Current research of action is limited concerning the sum of the particular conditions and conditions that achieve the sense of risk, the perfect ways to deal with assessing alertness as to partition, and the way caution unites through another harmful issues to impact mental wellness.

\section{DISCRIMINATION AND OTHER STRESS FACTORS}

Discrimination was associated to a lesser amount of sleep and greater sleep difficulties, self-regulating of socioeconomic status and additional stress factors, and can explanation for several of the race-related distinctions in sleep. (Slopen et al., 2014).

Discrimination should be explained in the references of different mechanisms of bigotry. Social detriments and stress factors frequently group in individuals and spots. Furthermore, institutional racism can lead to what, known as stress proliferation measures, wherein an early stress factor may start and intensify stress factor in different spaces of life. Along these lines, existing and working conditions made by prejudice can start and support distinctive disclosure to a wide scope of stress factors that, at face esteem, might not seem, by all accounts, to be identified with racism. They may incorporate "traditional stressors" like viciousness, illegal exploitation, neighborhood environment, the monetary pressure, and stress in relation. These are the "serious stressors," designed by societal detriment, that catch significant difficulties, clashes, and interruptions throughout everyday life, and are particularly harmful while they are persistent and repeat in significant societal jobs and spaces (Pearlin et al. 2005).

\section{CAPTURING “HIDDEN" ASPECTS OF RACE- RELATED STRESSORS ON MENTAL HEALTH}

Understanding the methods wherein the communal perspective of populace of color influences their psychological wellness needs in-depth and also extensive categorization of the exposure in their societal perspective so as to can influence wellbeing. The study highlights the various aspects wherein racism can 
influence psychological wellness. Some different issues related to race can likewise assume a part in determining the psychological health of distraught peoples, and we require to know the stress factors in their complete intricacy. Upcoming days studies should define that complete variety of threat factor and also sources which might be one-of-a-kind to or additional widespread amongst characterized race-related as well as cultural populaces and recognize exactly how they incorporate by everyone more than the life training path to influence outlines of psychological wellbeing. This type of observations should listen to the altering societal framework of race-related status as well as integrate arising dangers to psychological health in addition to opportunities that may occur to promote boosted psychological health. (David R. Williams 2018).

A relevant requirement is to offer an even more organized focus to experiences exactly how some beneficial encounters which are not associated to racism can undoubtedly show the results of racism and also to improved record their involvement to psychological health. For instance, the demise of a friend or family member is a regular marker of anxiety on ranges of life occasions, other than how such direct disclosure are constrain through bigger racism in the culture is not usually understand. A study related to neighborhood grief highlights the importance of the strategy. She revealed the structural problems connected to racism bring about reduced life expectation for African Americans. A outcome of the big race-related distinctions in life span which is difference to whites, black Americans are revealed additional fatalities of buddies and also relatives from very formative years by late life and also to even further fatalities earlier in the life For instance, contrast to whites, black youngsters are 3 times as most probable to lose a mommy from ten years old, and black adults are greater compare two times as most probable to shed a kid thirty years, and also a spouse from 60 years old ago. Umberson shows that this important value of grief, as well as loss of social connections, is a one-of-a-kind stress factor that harmfully influence stages of encouraging societal ties and also psychological (as well as physical health) throughout life course.(Umberson 2017).

The Criminal Justice system has too recognized like a tool of institutional racism, a communal structure which produced plans and processes that have discrepancy adverse impacts on labeled race-related populaces. A rising proof reveal that plans inside that classification that have differential influence on racerelated catageries are an example of institutional bigotry. With roughly 700 per 100,000 inhabitants put behind bars at any type of given time, the US has the biggest number as well as the charge of in prison populace worldwide (Wildeman and Wang 2017). The charge of imprison enhanced drastically in the 1970s. differences in surveillances and sentence have been connected by a tenfold enhancing in the danger of imprisonment for nonHispanic blacks contrast to white males in the US, typically assisted by plans which have parenthood outlawed drug mistreatment as well as a mental disease (Wildeman in addition to Wang 2017).

A current nationally representative, quasi-experimental research, discovered that authorities murders of unarmed black Americans aggravated psychological wellness amongst blacks in the general populace however had no impact on whites (Bor et al. 2018).

A research of 386 women obtaining treatment at a city university hospital reported on the location as well as the timing of experiencing cases of violent behavior in their communities. The research discovered that ladies who observed brutality in their neighborhood were two times as probable to information dejected as well as stress signs contrasted to those that reported no physical violence. There is likewise an arising body of proof that shows there might be an intricate pattern of organization in between the stress factor of societal aggression and psychological wellness, as a minimum for young people of color (Gaylord-Harden et al. 2017a, Gaylord-Harden et al. 2017b).

\section{CULTURAL RACISM AND MENTAL HEALTH}

Developing a society of health and wellness in addition to getting wellness equity requires that we consider social racism in an included substantial technique. Social therapies are normally referenced in wellness together with likewise wellness fascism scholarship, yet the empirical cosmetics usually drag the scholastic focus. Many cosmetics throughout strategies have in reality substantively included concepts of culture in addition to on top of that social therapy, the well worth of these therapies as parts of a system of racism, in addition to gadgets that may attach social threats to wellness. When integrated, these literary works utilize essential understandings right into techniques individuals wellness as well as likewise health could deal with the elegant trouble of eliminating racial variations in health as well as wellness and health.

Ultimately, the debates attaching to racism continue today, along with a similar means they still establish various scholastic spans along with techniques. In order to information, as well as an arranged specialist framework when it concerned social racism, along with numerous other terms that are based upon contemporary racism, inquiries that require included evaluation are taking place. 
They refer, on one hand, to scholastic approaches in addition to adding a lot added certain wrap-ups worrying about the variables that protect racism along with on top of that have in racist thinking, provided that on the certified together with "neutral" degrees racism asks for to bid farewell to exist. On the different lots of hands, there would definitely be analyses important that can develop benefits along with functional searchings for along with results needed for relied on anti-racist methods along with treatments. (SimonaRodat, 2017).

Whitley (2015) summarize the around the world job for emotional wellness as well as also furthermore health (Lancet Global Mental Wellness Along With Health And Wellness Group, 2008): its background in addition to added valuable settlements in addition to conversations called its stopping working to recommend society along with similar context, with the attendant risks of pragmatic retiring as well as also furthermore establishing worries of top-down expansionism. He points out that principles of emotional suffering along with moreover healing normally differ along with a facility in all countries along with in addition in multi-cultural societies. In various places, Western biomedical variants of problem do not make an excellent feeling to everyday people along with aboriginal professionals.

Carpenter-Song (2015) urges us that disregarding society along with context prevails in the U.S.A. in a similar way, which overreliance on a slim clinical requirement has, actually, injured the extraordinary top-notch mental health care. Huge quantities of individuals obtain drugs in comparison to the psychosocial preserves they try to find (Honberg et al. 2011).

One indication of the resolution of racism in society is the high degrees of unfavorable stereotype in people. An existing throughout the country research study videotaped that it is not merely developed individuals of refuted racerelated grouping that are stereotyped pessimistically, however, moreover, kids (aged 0 to 8 years) along with adding the adolescence of color in the US encounter high stages of undesirable race-related stereotyping from miss that handle them (Clergyman et al. 2018). Unfavorable stereotyping by whites was most noticeable towards miss, nonetheless, was seen also in the direction of young people. As situations, young black young people (aged 0-8 years) were practically 3 times much more possible than white to miss out on being positioned as slouching, with Aboriginal Americans in addition to addition Hispanic youngsters moreover more possible to be considered negligent than white grown-ups.

\section{WEATHER CHANGE, ECOLOGICAL RISKS, AND MENTAL HEALTH}

As we aim to the upcoming days, that is too crucial to provide interest to evaluating the psychological strength repercussions of the stress factors which might arise from natural as well as manmade calamities. For instance, a regular monthly study in Flint, Michigan, while of the current water situation, located that area participants reported stress, stress and anxiety, anxiety and worry wherein the area during continuous disaster (Cuthbertson et al. 2016).

These adverse psychological wellness effects were deemed to be associated not just with the real pollution of the water however additionally with mistrust of the main reaction to the situation and also the insufficiency of their reaction (Cuthbertson et al. 2016). likewise, an evaluation of a study on the psychological wellness influence of a terrible quake in Japan in 2011 located long-lasting adverse psychological wellness influence for the populace influenced (Ando et al. 2017). While post distressing anxiety signs had a tendency to refuse gradually, as well as first boosts in suicide lowered. These searching recommend the requirement for lasting and recurring mental wellness support for communities as well as populaces that deal with high degrees of direct exposure to traumatic experiences.

\section{PROTECTIVE FACTORS}

Some research have determined psychological and societal sources which can minimize the unfavorable results from anxiety of separation on psychological wellness. Spiritual participation has decreased the adverse impacts of separations on wellness in 2 nationwide researches. In potential evaluations utilizing data as of the NSBA, greater stages of spiritual association decreased the favorable connection amid race-related discrimination as well as mental anxiety (Ellison, Musick and Henderson 2008). In the nationwide MIDUS research, church participation buffered the unhelpful result of discrimination on harmful impact amongst African-Americans however not amongst Whites (Bierman 2006).

Much more study is needed to determine the components of these difficulties as well as recognize just how they can be efficiently resolved. Current research (Edwards et al. 2017) of three hundred sixty five arising grownups (96\% African American), eighteen to twenty yrs of ageconnected from a college in a northeastern city location, clarifies the substantial difficult obstacles that young people regard. The young people observed that their largest problems were hostile policing, high stages of area physical violent behavior, and the insecurity of their real 
estate. These young people revealed that they dealt with continuous risk and horror, elevated ranges of sadness, as well as a reduced supposed economic chance. Hence, they resided in the small since of their unpredictability regarding their upcoming days. Altering the existing route of anxiety and mental health issue will certainly call for substantial financial investment in making it possible for youth to expand abilities and resources to challenge as well as cope with the stressors they encounter.

\section{EMERGING MENTAL HEALTH CHALLENGES}

There is proof of huge in addition to amplifying mental wellness along with wellness challenges for minority youngsters. Self-destruction information is illustratory. Indigenous Americans have the most effective rate of selfdestruction. It is the 8th leading factor of casualty full quantity along with likewise the second leading variable (Odafe et al. 2016).

Rates of frame of mind problems, together with the suicide-related outcomes, have in truth increased substantially among young adults along with young people, along with the rise of social networks sites network web sites, which can be responsible. The mental illness jumps on the boost among young adults along with on top of that youths, in addition to social media sites net sites networks might be a chauffeur behind the boost. According to a new research study, offered by the American Psychological Organization, expenses of prospective issues together with suicide-related outcomes have in fact boosted significantly over the ins 2014 amongst this age, affecting ladies, additionally, to include those that are wealthier, particularly. (Rosenberg, 2019). With boosts in mental illness focused among teenagers in addition to furthermore children, "completion results advise that social trends in the last ten years could have had a bigger outcome on the frame of mind problems in addition to a suicide-related result among a lot a lot more lively individuals contrasted to older individuals," according to the researchers.

A most likely recap can be the bundled increase in socials media, they mentioned. Along with being a great deal less excellent than more than likely to link directly, those that take full advantage of social media sites networks on a regular basis continue to be in enhancement a lot more perhaps to be included with cyber-bullying, which has really been connected to stress, self-harm, self-destructive recommendations. (Twenge, 2019).

\section{CONCLUSION}

Recognizing the methods through the societal framework of populaces of color influences their mental health needs comprehensive and full description of the disclosure in their communal framework which may influence wellness. A review of the study offered now several methods wherein racism may influence mental health. Various problems connected to race and also ethnic culture may too contribute in fit the mental wellness of deprived populaces, and we require to recognize these stress factors in their complete intricacy. The upcoming days study should identify that complete variety of threat aspects and sources that might be special too, or extra widespread amongst, stigmatized race-related and also ethnic populaces and also recognize how they integrate by reinforced, above the life program, to influence outline of psychological health. That type of research has to listen to the altering societal framework of race-related standing and integrate arising risks to psychological wellness in addition to changes that might occur to advertise enhanced mental health and wellness.

\section{REFERENCES}

[1] Mental Health America Achieves Milestone of 5 Million Mental Health Screenings. (2020, May 21). Retrieved June 23, 2020, from https://www.mhanational.org/mental-healthamerica-achieves-milestone-5-million-mental-healthscreenings.

[2] Pager D, Shepherd H. The sociology of discrimination: Racial discrimination in employment, housing, credit, and consumer markets. Ann Rev Sociol 2008:181-209.

[3] Williams DR, Mohammed SA. Discrimination and racial disparities in health: evidence and needed research. J Behav Med 2009;32:20-47.

[4] Williams DR, Lavizzo-Mourey R, Warren RC. The concept of race and health status in America. Public Health Rep 1994;109:26-41.

[5] Paradies Y. A systematic review of empirical research on self-reported racism and health.Int $\mathrm{J}$ Epidemiol 2006;35:888-901.

[6] Lewis TT, Kravitz HM, Janssen I, Powell LH. Self-reported experiences of discrimination and visceral fat in middleaged African-American and Caucasian women. Am J Epidemiol 2011;173:1223-31.

[7] Hunte HER. Association between perceived interpersonal everyday discrimination and waist circumference over a 9year period in the midlife development in the United States Cohort Study. Am J Epidemiol 2011;173:1232-9.

[8] Williams David R. and Mohammed Selina A. 2013 "Racism and Health I: Pathways and Scientific Evidence." American Behavioral Scientist 57(8):1152-73.

[9] Buxton OM, Marcelli E. Short and long sleep are positively associated with obesity, diabetes, hypertension, and 
cardiovascular disease among adults in the United States. SocSci Med 2010;71:1027-36

[10] Everson CA. Sustained sleep-deprivation impairs hostdefense. Am J Physiol 1993;265:R1148-54.

[11] Ackermann K, Revell VL, Lao O, Rombouts EJ, Skene DJ, Kayser M. Diurnal rhythms in blood cell populations and the effect of acute sleep deprivation in healthy young men. Sleep 2012;35:933-40.

[12] Ayas NT, White DP, Al-Delaimy WK, et al. A prospective study of selfreported sleep duration and incident diabetes in women. Diabetes Care 2003;26:380-4.

[13] Van Cauter E, Holmback U, Knutson K, et al. Impact of sleep and sleep loss on neuroendocrine and metabolic function.Horm Res 2007;67:2-9.

[14] Pager Devah and Shepherd Hana 2008 "The Sociology of Discrimination: Racial Discrimination in Employment, Housing, Credit, and Consumer Markets." Annual Review of Sociology 34:181-209.

[15] Ayas NT, White DP, Manson JE, et al. A prospective study of sleep duration and coronary heart disease in women. Arch Intern Med 2003;163:205-9.

[16] Qureshi AI, Giles WH, Croft JB, Bliwise DL. Habitual sleep patterns and risk for stroke and coronary heart disease: A 10-year follow-up from NHANES I. Neurology 1997;48:904-11.

[17] Connor J, Norton R, Ameratunga S, et al. Driver sleepiness and risk of serious injury to car occupants: population based case control study. Br Med J 2002;324:1125-8A

[18] Ford DE, Cooper-Patrick L. Sleep disturbances and mood disorders: An epidemiologic perspective. Depress Anxiety 2001;14:3-6.

[19] Crum RM, Storr CL, Chan YF, Ford DE. Sleep disturbance and risk for alcohol-related problems. Am J Psychiatry 2004;161:1197-203.

[20] Natalie Slopen, ScD1,2; David R. Williams, Discrimination, Other Psychosocial Stressors, and Self-Reported Sleep Duration and Difficulties 2014 SLEEP, Vol. 37, No. 1.

[21] Dohrenwend Bruce P. Dohrenwend Barbara S. 1969, Social Status and Psychological Disorder: A Casual Inquiry. New York: Wiley.

[22] Vega William A. and Rumbaut Ruben G. 1991 "Ethnic Minorities and Mental Health." Annual Review of Sociology 17:351-83.

[23] Hughes Michael and Thomas Melvin E. 1998 "The Continuing Significance of Race Revisited: A Study of Race, Class, and Quality of Life in America, 1972 to 1996." American Sociological Review 63:785-95.

[24] Keyes Corey LM 2007 "Promoting and Protecting Mental Health as Flourishing: A Complementary Strategy for Improving National Mental Health.” American Psychologist 62(2):95-108. [PubMed: 17324035]

[25] Miranda Jeanne, McGuire Tomas G., Williams David R. and Wang Philip 2008 "Mental Health in the Context of Health Disparities." American Journal of Psychiatry 165(9):1102-8. doi: 10.1176/ appi.ajp.2008.08030333 [PubMed: 18765491]

[26] Breslau Joshua, Kendler Kenneth S., Su Maxwell, GaxiolaAguilar Sergio and Kessler Ronald C. 2005 "Lifetime Risk and Persistence of Psychiatric Disorders across Ethnic Groups in the United States." Psychological Medicine 35(3):317-27. [PubMed: 15841868]

[27] Krieger Nancy 1999 "Embodying Inequality: A Review of Concepts, Measures, and Methods for Studying Health Consequences of Discrimination." International Journal of Health Services 29(2): 295-352. [PubMed: 10379455]

[28] Williams David R., Neighbors Harold W. and Jackson James S. 2003 "Racial/Ethnic Discrimination and Health: Findings from Community Studies." American Journal of Public Health 93(2):200- 8. [PubMed: 12554570]

[29] Lewis Tené T., Cogburn Courtney D. and Williams David R. 2015 "Self-Reported Experiences of Discrimination and Health: Scientific Advances, Ongoing Controversies, and Emerging Issues." Annual review of clinical psychology 11:407-40. doi: 10.1146/annurev-clinpsy-032814-112728.

[30] MouzonDawne M. 2017 "Religious Involvement and the Black-White Paradox in Mental Health." Race and Social Problems 9(1):63-78.

[31] Gee Gilbert C., Spencer Michael, Chen Juan, Yip Tiffany and Takeuchi David T. 2007 "The Association between Self-Reported Racial Discrimination and 12-Month Dsm-Iv Mental Disorders among Asian Americans Nationwide." Social Science \& Medicine 64(10):1984-96. [PubMed: 17374553]

[32] Oh Hans, Yang Lawrence H., Anglin Deidre M. and DeVylder Jordan E. 2014 "Perceived Discrimination and Psychotic Experiences across Multiple Ethnic Groups in the United States." Schizophrenia Research 157(1-3):259-65. doi: 10.1016/j.schres.2014.04.036. [PubMed: 24856412]

[33] MoomalHashim, Jackson Pamela B., Stein Dan. J., Herman Allen, Myer Landon, SeedatSoraya, Madela-Mntla Edith and Williams David R. 2009 "Perceived Discrimination and Mental Health Disorders: The South African Stress and Health Study." South African Medical Journal 99(5 Pt 2): 383-9. [PubMed: 19588802]

[34] Wallace Stephanie, Nazroo James and BécaresLaia 2016 "Cumulative Effect of Racial Discrimination on the Mental Health of Ethnic Minorities in the United Kingdom." American Journal of Public Health 106(7):1294-300. doi: 10.2105/AJPH.2016.303121. [PubMed: 27077347].

[35] Priest, Naomi, Yin Paradies, BrigidTrenerry, Mandy Truong, Saffron Karlsen, and Yvonne Kelly. 2013. "A Systematic Review of Studies Examining the Relationship between Reported Racism and Health and Wellbeing for Children and Young People." Social Science \& Medicine 95:115-27

[36] Brody, Gene H., Tianyi Yu, Edith Chen, Gregory E. Miller, Steven M. Kogan, and Steven R. H. Beach. 2013. "Is Resilience Only Skin Deep? Rural African Americans' Socioeconomic Status-related Risk and Competence in Preadolescence and Psychological Adjustment and Allostatic Load at Age 19." Psychological Science 24(7):1285-93.

[37] Gibbons, Frederick X., Meg Gerrard, Michael J. Cleveland, Thomas A. Wills, and Gene Brody. 2004. "Perceived Discrimination and Substance Use in African American 
Parents and Their Children: A Panel Study." Journal of Personality and Social Psychology 86(4):517-29.

[38] Murry, Velma McBride, Mia S. Bynum, Gene H. Brody, Amanda Willert, and Dionne Stephens. 2001. "African American Single Mothers and Children in Context: A Review of Studies on Risk and Resilience." Clinical Child and Family Psychology Review 4(2):133-55.

[39] ShervinAssari, EhsanMoazen-Zadeh, Cleopatra Howard Caldwell and Marc A. Zimmerman2017. Racial Discrimination during Adolescence Predicts Mental Health Deterioration in Adulthood: Gender Differences among Blacks ORIGINAL RESEARCH article Front. Public Health, $29 \quad$ May 2017 https://doi.org/10.3389/fpubh.2017.00104

[40] Mary S. Himmelstein , Danielle M Young, Diana T Sanchez, James S. Jackson's , 2015Vigilance in the Discrimination-Stress Model for Black Americans. Psychology \& Health 30(3):253-267, DOI:10.1080/08870446.2014.966104

[41] Williams, David R., RisaLavizzo-Mourey, and Rueben C. Warren. 1994. "The Concept of Race and Health Status in America." Public Health Reports 109(1):26. Williams, David R., and Selina A. Mohammed. 2009.

[42] Williams, David R., Yan Yu, James S. Jackson, and Norman B. Anderson. 1997. "Racial Differences in Physical and Mental Health: Socioeconomic Status, Stress, and Discrimination." Journal of Health Psychology 2(3):335-51.

[43] Clark, Rodney, Ramona A. Benkert, and John M. Flack. 2006. "Large Arterial Elasticity Varies as a Function of Gender and Racism-related Vigilance in Black Youth." Journal of Adolescent Health 39(4):562-69.

[44] Hicken, Margaret T., Hedwig Lee, and Anna K. Hing. 2018. "The Weight of Racism: Vigilance and Racial Inequalities in Weight-related Measures." Social Science \& Medicine 199:157-66.

[45] LaVeist, Thomas A., Roland J. Thorpe, Jr., Geraldine Pierre, GiShawn A. Mance, and David R. Williams. 2014. "The Relationships among Vigilant Coping Style, Race, and Depression." Journal of Social Issues 70(2):241-55.

[46] Perfect, T. J., \& Schwartz, B. L. (Eds.) (2002). Applied metacognition Retrieved from http://www.questia.com/read/107598848

[47] Myers, D. G. (2007). Psychology(1stCanadian ed.). New York, NY: Worth.

[48] Cognition.(2008). In Oxford reference online premium dictionary. Retrieved from http://www.oxfordreference.com

[49] Blue, L. (2008, March 12).Is our happiness preordained? [Online exclusive]. Time. Retrieved from http://www.time.com/time/health

[50] J. Clerk Maxwell, A Treatise on Electricity and Magnetism, 3rd ed., vol. 2. Oxford: Clarendon, 1892, pp.68-73.

[51] I. S. Jacobs and C. P. Bean, "Fine particles, thin films and exchange anisotropy," in Magnetism, vol. III, G. T. Rado and H. Suhl, Eds. New York: Academic, 1963, pp. 271-350.

[52] K. Elissa, "Title of paper if known," unpublished.

[53] R. Nicole, "Title of paper with only first word capitalized," J. Name Stand. Abbrev., in press.
[54] David R. Williams. Stress and the Mental Health of Populations of Color: Advancing Our Understanding of Race-related Stressors . Journal of Health and Social Behavior , 2018, Vol. 59(4) 466-485

[55] Umberson Debra 2017 "Black Deaths Matter: Race, Relationship Loss, and Effects on Survivors." Journal of Health and Social Behavior 58(4):405-20. [PubMed: 29172766]

[56] Wildeman Christopher and Wang Emily A. 2017 "Mass Incarceration, Public Health, and Widening Inequality in the USA." The Lancet 389(10077):1464-74

[57] Gaylord-Harden Noni K., So Suzanna, Bai Grace J., Henry David B. and Tolan Patrick H. 2017a "Examining the Pathologic Adaptation Model of Community Violence Exposure in Male Adolescents of Color." Journal of Clinical Child \& Adolescent Psychology 46(1):125-35. [PubMed: 27653968]

[58] Gaylord-Harden Noni K., So Suzanna, Bai Grace J. and Tolan Patrick H. 2017b "Examining the Effects of Emotional and Cognitive Desensitization to Community Violence Exposure in Male Adolescents of Color." American Journal of Orthopsychiatry 87(4):463-73. [PubMed: 27977283].

[59] SimonaRodat Cultural Racism: A Conceptual Framework. RSP, No. 54, 2017: 129-140

[60] Cuthbertson Courtney A., Newkirk Cathy, Ilardo Joan, Loveridge Scott and Skidmore Mark. 2016 "Angry, Scared, and Unsure: Mental Health Consequences of Contaminated Water in Flint, Michigan.” Journal of Urban Health: Bulletin of the New York Academy of Medicine 93(6):899- 908. doi: 10.1007/s11524-016-0089-y. [PubMed: 27807700]

[61] Ando Shuntaro, Kuwabara Hitoshi, Araki Tsuyoshi, Kanehara Akiko, Tanaka Shintaro, Morishima Ryo, Kondo Shinsuke and Kasai Kiyoto. 2017 "Mental Health Problems in a Community after the Great East Japan Earthquake in 2011: A Systematic Review." Harvard review of psychiatry 25(1): 15-28. doi: 10.1097/hrp.0000000000000124. [PubMed: 28059933]

[62] Ellison Christopher G., Musick Marc A. and Henderson Andrea K. 2008 "Balm in Gilead: Racism, Religious Involvement, and Psychological Distress among African-American Adults." Journal for the Scientific Study of Religion 47(2):291-309.

[63] Bierman Alex. 2006 "Does Religion Buffer the Effects of Discrimination on Mental Health?Differing Effects by Race." Journal for the Scientific Study of Religion 45(4):551-65.

[64] Ellison Christopher G., Musick Marc A. and Henderson Andrea K. 2008 "Balm in Gilead: Racism, Religious Involvement, and Psychological Distress among African-American Adults." Journal for the Scientific Study of Religion 47(2):291-309.

[65] Bierman Alex. 2006 "Does Religion Buffer the Effects of Discrimination on Mental Health?Differing Effects by Race." Journal for the Scientific Study of Religion 45(4):551-65.

[66] Odom Erica C., Vernon-Feagans Lynne and Family Life Project Key Investigators. 2010 "Buffers of Racial 
Discrimination: Links with Depression among Rural African American Mothers." Journal of Marriage and Family 72(2):346-59. [PubMed: 20672013]

[67] Edwards Lorece V., Lindong Ian, Brown Lawrence, Hawkins Anita S., Dennis Sabriya, Fajobi Olaoluwa, Rowel Randolph, Braithwaite Ronald and Sydnor Kim D. 2017 "None of Us Will Get out of Here Alive: The Intersection of Perceived Risk for Hiv, Risk Behaviors and Survival Expectations among African American Emerging Adults." Journal of Health Care for the Poor and Underserved 28(2):48-68. [PubMed: 28458264]

[68] Twenge J, Cooper A, Joiner T, Duffy M, Binau S. Age, period, and cohort trends in mood disorder indicators and suicide-related outcomes in a nationally representative dataset, 2005-2017 [published online March 14, 2019]. J Abnorm Psychol. doi:10.1037/abn0000410.

\section{AUTHOR'S PROFILES}

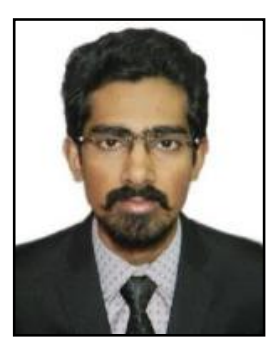

RAJESH RISHI, a B. Tech graduated student of Electrical and Electronics Engineering from Assam Don Bosco University, Assam, India. $\mathrm{He}$ is from Assam, India. His field of interests are smart grid control, renewable energy, power quality, microgrid, electrical machines and drives, and sensor-less motor control. He is also interested in microcontroller, IOT, electroencephalogram (EEG) and artificial intelligence. Currently he has made a Brainwave Maneuvered Wheelchair and Brainwave Based Password Authentication using electroencephalogram (EEG) and has also designed a Smart Helmet Using Arduino to Reduce Road Accidents, and Face Mask Detector for Covid19 using AI. He is fondling and effectively outbidding his passion for writing. He is a voracious reader who has managed to amass a small library for himself over the course of many years.

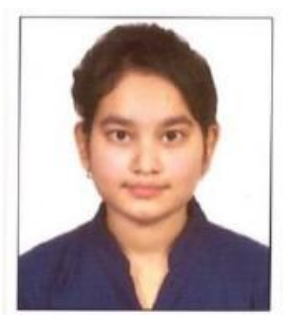

PINKI DOLOI, a B.Tech graduated student from North Eastern Regional Institute of Science \& Technology (NERIST), Arunachal Pradesh specialization in Computer Science Engineering from India. She has done her diploma in Computer Engineering from Assam, India. Some of the projects completed by her are Home Automation Using Google Assistant, Face Mask Detector for Covid19, Music Lyrics Application, Daily Expense Tracker, etc. Her interest is Data Science, IoT, Artificial Intelligence, Web Development, Python, Electronic devices and circuits, and Circuit Debugging, etc. She is outbidding her own love for writing, which she is very effective in doing so. She is a keen reader and has amassed a sizable library for herself. 